\title{
Ultrasonic preparation improves outcome in apical surgery
}

\author{
When patients need apical surgery, is root-end preparation with ultrasonic \\ devices as effective as the round dental bur?
}

\section{de Lange J, Putters T, Baas EM, van Ingen JM.}

Ultrasonic root-end preparation in apical surgery: a prospective randomized study. Oral Surg Oral Med Oral Pathol Oral Radiol Endod 2007; 104:841-845.

Design This was a randomised controlled trial (RCT).

Intervention Root-end resection and preparation with a round dental bur was compared with the use of ultrasonic diamond coated retro-tips.

Outcome measure Treatment was considered a success when the radiological and clinical criteria listed (Table 1) were met.

Table 1. Criteria for successful treatment

\begin{tabular}{l|l}
\hline Radiological & Clinical \\
\hline $\begin{array}{l}\text { Lamina dura around apex } \\
\text { of tooth is visible; all roots } \\
\text { investigated separately }\end{array}$ & No fistula or pockets to the apex \\
\hline $\begin{array}{l}\text { The periodontal space around } \\
\text { the apex is } \leq 2 \text { times the } \\
\text { periodontal space at the } \\
\text { nontreated part of the root. }\end{array}$ & $\begin{array}{l}\text { No percussion sensitivity of the } \\
\text { tooth }\end{array}$ \\
\hline $\begin{array}{l}\text { Bone defect seen immediately } \\
\text { after treatment is filled with new } \\
\text { bone not necessarily of same } \\
\text { opacity as surrounding bone }\end{array}$ & $\begin{array}{l}\text { Tooth is functional, with no } \\
\text { impairment or complaints made }\end{array}$ \\
\hline $\begin{array}{l}\text { Small apical defect in lamina dura } \\
\text { of maximum of } 1 \text { mm }{ }^{2} \text { at side of } \\
\text { apical filling is acceptable }\end{array}$ & $\begin{array}{l}\text { Aspect of the scar tissue and } \\
\text { gingival tissue (no signs of } \\
\text { infection) }\end{array}$ \\
\hline
\end{tabular}

Results Out of a total group of 399 patients who were included in the study, adequate followup could be obtained in 290 patients. The overall success rate in the ultrasonic group was $80.5 \%$ and in the group treated with a bur was $70.9 \%$ (P 0.056). In molars, the difference in success rate was significant (P 0.02).

Conclusions The use of an ultrasonic device in apical surgery showed a clear benefit over the traditional treatment. Especially in molars, the results were significant.
Address for correspondence: Jan de Lange, Isala Clinics, Department of Oral and Maxillofacial Surgery, Groot Wezenland 20, 8000 GM Zwolle, The Netherlands. E-mail: lotte.jan@wxs.nl

\section{Commentary}

The clinical outcome of endodontic treatment is not always successful. Endodontic surgery is a treatment option for periapical lesions, and differences in previously reported success rates of endodontic surgery ranged from $44-95 \%$. This wide range in success rates is partly because of differences in the criteria used for assessment of success, and partly because of variation in methods used, such as apical canal preparation, retrograde-filling materials and surgical technique.

The authors here report a RCT examining differences in clinical outcome between traditional retrograde preparation of the canal with a bur versus retrograde canal preparation with an ultrasonic device (P-Max Newtron; Satelec, Merignac, France) for endodontic retreatment of periradicular lesions. This study methods were welldesigned. Fourteen months of followup was adequate to evaluate the clinical outcome of these procedures, with only $24.4 \%$ of patients excluded in ultrasonic and $30.2 \%$ in bur group, respectively.

The traditional surgical procedure of using burs produces consistently lower success rates for molars than for front teeth and premolars, both here and in previous studies. This is mainly because of the limitations to visibility and accessibility in the back teeth. In the molar area, apical preparation in the appropriate direction to adequate depth and at the correct position is challenging because of the fixed angulation and mechanics of dental drills. Ultrasonic devices give better results in molar and premolar teeth than burs, possibly partly because of the small and narrow ultrasonic tip which allows easier access to these teeth than burs.

Previous retrospective studies also demonstrated advantages in using an ultrasonic device for apical surgery, although those studies lacked coherence beyond retrograde preparation of the canal, such as the use of microscope, retro-filling materials and operator's specialty. ${ }^{1,2}$ This study is the first prospective RCT to compare traditional root apex preparation and ultrasonic apex preparation, even though ultrasonic devices were introduced to apical surgery more than 30 years ago. Based on this well-conducted trial, surgical endodontic treatment using ultrasonic tips significantly improves outcomes compared with the traditional bur technique, especially in molar teeth where the access to the root end becomes more difficult.

\section{Toru Naito}

Department of General Dentistry, Fukuoka Dental College, Fukuoka, Japan

1. Tsesis I, Rosen E, Schwartz-Arad D, Fuss Z. Retrospective evaluation of surgical endodontic treatment: traditional versus modern technique. J Endod 2006; 32:412-416.

2. Testori T, Capelli M, Milani S, Weinstein RL. Success and failure in periradicular surgery: a longitudinal retrospective analysis. Oral Surg Oral Med Oral Pathol Oral Radiol Endod 1999; 87:493-498.

Evidence-Based Dentistry (2008) 9, 53. doi:10.1038/sj.ebd.6400585 